\title{
Seroprevalence, correlates, and characteristics of undetected coeliac disease in England
}

\author{
J West, R F A Logan, P G Hill, A Lloyd, S Lewis, R Hubbard, R Reader, G K T Holmes, \\ K-T Khaw
}

See end of article for authors' affiliations

Correspondence to:

West, University of

Nottingham, Division of

Epidemiology and Public

Health, Medical School,

Queen's Medical Centre,

Nottingham NG7 2UH

UK;

joe.west@nottingham.ac.uk

Accepted for publication 31 January 2003

\begin{abstract}
Objective: To examine the seroprevalence, correlates, and characteristics of undetected coeliac disease in a large adult population sample in Cambridge, UK.

Methods: The Cambridge General Practice Health Study invited individuals from 12 general practices, aged 45-76 years, to attend for a health survey that included a bone density measurement, between 1990 and 1995. A total of 7550 participants' serum samples were tested for antiendomysial antibody (EMA). Seroprevalence of undetected coeliac disease was based on EMA positivity. Differences between EMA positive and negative participants of various physiological correlates and reported characteristics were estimated by multivariate logistic and linear regression and adjusted for age, sex, social class, and smoking behaviour.

Results: The seroprevalence of undetected coeliac disease in this general population sample aged 45-76 was $1.2 \%(95 \%$ confidence interval (CI) $0.9-1.4)$. EMA positive participants $(n=87)$ were on average slightly lighter by $2.2 \mathrm{~kg}(\mathrm{p}=0.08)$, were more likely to have reported their general health as being "good or excellent" (odds ratio (OR) $1.76(95 \% \mathrm{Cl} 0.90-3.46)$ ), and were less likely to report being a current smoker (OR for current versus never $0.36(95 \% \mathrm{Cl} 0.14-0.90)$ ) than EMA negative participants. EMA positivity was associated with an $8 \%$ reduction in mean serum cholesterol 10.5 $\mathrm{mmol} / \mathrm{l} ; \mathrm{p}<0.01)$ and reductions in mean haemoglobin $(0.3 \mathrm{~g} / \mathrm{dl} ; \mathrm{p}<0.01)$, total protein $(1.0 \mathrm{~g} / \mathrm{l}$; $p<0.05)$, and corrected serum calcium $(0.02 \mathrm{mmol} / \mathrm{l} ; \mathrm{p}<0.05)$. There was an increased risk of osteoporosis in EMA positive participants (OR $3.1(95 \% \mathrm{Cl} 1.3-7.2)$ ) and of mild anaemia (OR 4.6 (95\% $\mathrm{Cl}$ 2.5-8.2)) compared with EMA negative participants.

Conclusions: Undetected coeliac disease is likely to affect approximately $1 \%$ of the population of England aged 45-76 years, a value similar to several other countries. Those affected report "better health" but they do have an increased risk of osteoporosis and mild anaemia. In contrast, they have a favourable cardiovascular risk profile that may afford protection from ischaemic heart disease and stroke.
\end{abstract}

T he development of serological tests for the diagnosis of coeliac disease, including tests for endomysial and tissue transglutaminase antibodies, has made screening for coeliac disease a realistic possibility. ${ }^{12}$ Several studies, mainly from Europe but also from South America and Australasia, using various tests, have shown that considerable numbers of people may have undetected coeliac disease. ${ }^{3-11}$ The implications of this diagnosis are unclear as currently the few reported data on the morbidity and physiological characteristics associated with previously undetected disease are from small selected case series. ${ }^{12}{ }^{13}$ Most adult screening studies in the general population have identified only small numbers of previously undiagnosed cases and have therefore been unable to examine these issues.

We have studied a large adult general population sample recruited from the Cambridge area to quantify the seroprevalence, characteristics, and physiological correlates of undetected coeliac disease.

\section{METHODS}

\section{Participants}

The Cambridge General Practice Health Study identified all individuals irrespective of health status aged 45-76 years registered with 12 general practices and invited them for a health survey and bone density measurement between 1990 and 1995. ${ }^{14-16}$ Briefly, all those consenting completed a health and lifestyle questionnaire that included questions on occupation, past medical history, cigarette smoking habit, and whether they rated their general health as "excellent, good, moderate, or poor". They were also asked about known illnesses, for example self reported cardiovascular disease was defined as reporting of any one or more of the following conditions: heart attack, angina, high blood pressure, and stroke. Participants then attended for a physical examination, including measurement of blood pressure and bone mineral density (BMD), the latter measured at the total hip, and total spine by dual energy $x$ ray absorptiometry, using the Hologic QDR-1000 densitometer (Hologic, Waltham, Massachusetts, USA). Blood samples were obtained by venepuncture and serum lipids were measured in fresh samples at the Hinchingbrooke Hospital biochemistry laboratory. All participants have been flagged at the Office of National Statistics for mortality and have been followed up to the end of May 2001. Death certificates were coded according to the 9th Revision of the International Classification of Diseases. We were unable to gain access to participants for the purposes of duodenal biopsy. The study was approved by the Cambridge District Local Research Ethics Committee

Abbreviations: EMA, antiendomysial antibody; transglutaminase antibody; ELISA, enzyme linked immunosorbent assay; $\mathrm{BMI}$, body mass index; BMD, bone mineral density. 


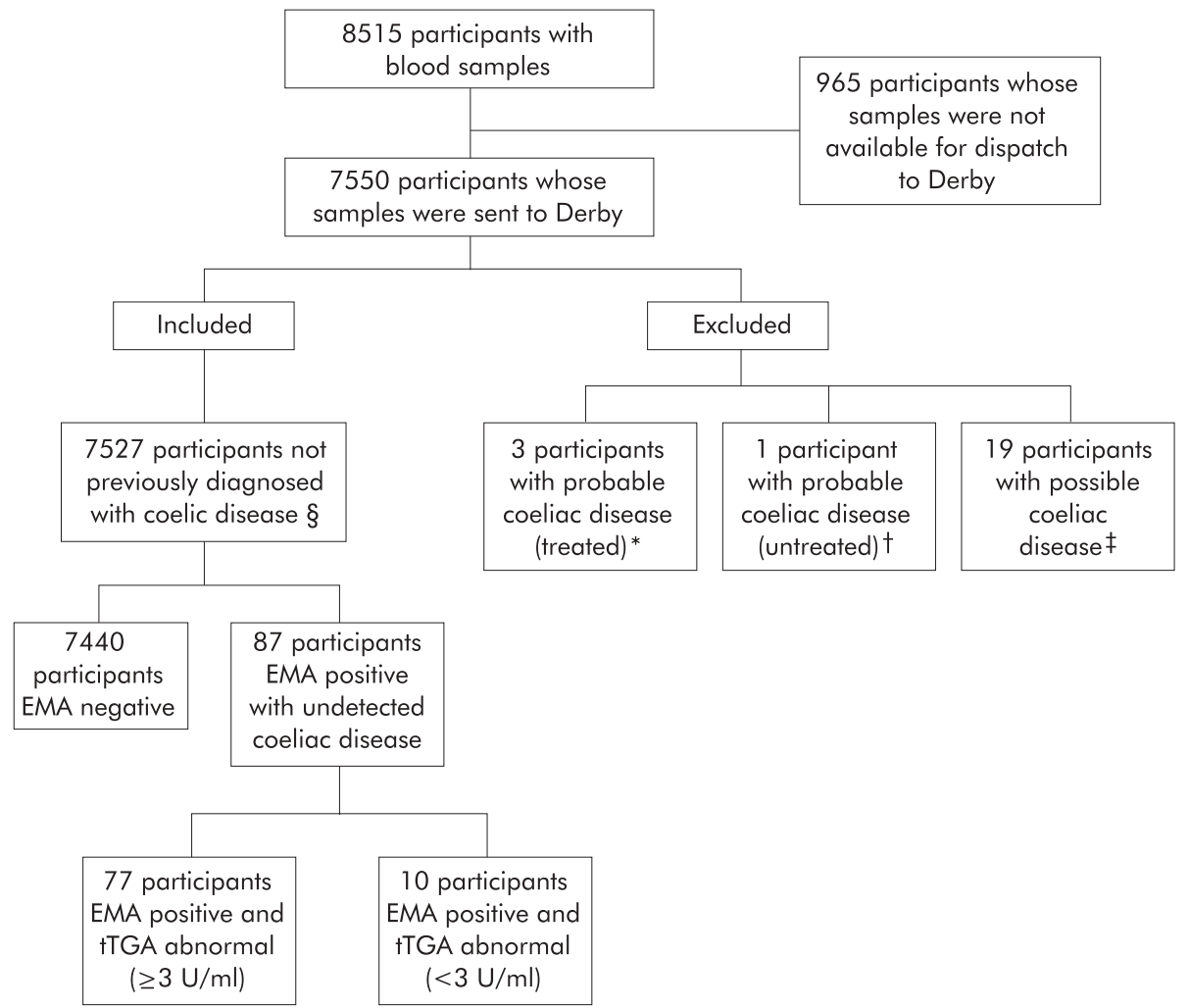

Figure 1 Overview of study participants. *Participants with probable coeliac disease (treated) - those who reported taking a gluten free diet and having a medical condition coded as malabsorption (including coeliac disease) and who were antiendomysial antibody (EMA) negative. †Participants with probable coeliac disease (untreated) - those who reported having a medical condition coded as malabsorption (including coeliac disease) but did not report taking a gluten free diet, and who were EMA positive. $¥$ Participants with possible coeliac disease-those who reported taking a gluten free diet but did not report having a medical condition coded as malabsorption (including coeliac disease) and who were EMA negative. §Participants not previously diagnosed with coeliac disease-those that did not report being on a gluten free diet, or having any other medical condition coded as malabsorption (including coeliac disease). This group was further subdivided into those who were EMA negative (no evidence of coeliac disease) and those who were EMA positive (undetected coeliac disease). The latter group was further subdivided on the basis of human antitissue transglutaminase antibody (tTGA) results

\section{Serology}

We used IgA class antiendomysial antibody (EMA) as our marker of undetected coeliac disease as it has a reported specificity of $99 \% .{ }^{17}$ As there is the possibility of false positive results, we used a second serological marker, human antitissue transglutaminase antibody (tTGA), to validate the positive samples. All sera $(\mathrm{n}=7550)$ were investigated for the presence of EMA using indirect immunofluorescence on commercial monkey oesophagus sections (The Binding Site, Birmingham, UK), using a 1 in 10 serum dilution. A positive control was included with every batch of 40 samples. Samples positive for EMA were further tested for tTGA using a commercially available quantitative ELISA kit (Celikey; Pharmacia Diagnostics AB, Freiburg, Germany). We considered results of $<3 \mathrm{U} / \mathrm{ml}$ to be negative based on the experience in our laboratory. We measured total serum IgA in all sera and considered results of $<0.05 \mathrm{~g} / \mathrm{l}$ to indicate selective IgA deficiency.

\section{Definitions}

We defined undetected coeliac disease as those participants without self reported coeliac disease that were EMA positive. Definitions for the presence or absence of coeliac disease in participants are given in fig 1 .

Social class was coded from the highest reported occupation of the participant or their spouse and grouped as: professional and managerial, lower professional (group 1); non- manual skilled, manual skilled (group 2); partly skilled, unskilled, armed forces, inadequately described, housewife/homemaker, retired (group 3).

Participants were defined as having osteoporosis if their BMD measurement was 2.5 standard deviations (SD) or more

Table 1 Seroprevalence of undetected coeliac disease using antiendomysial antibody (EMA) and human antitissue transglutaminase ( $\mathrm{TTGA})$ tests by age and sex

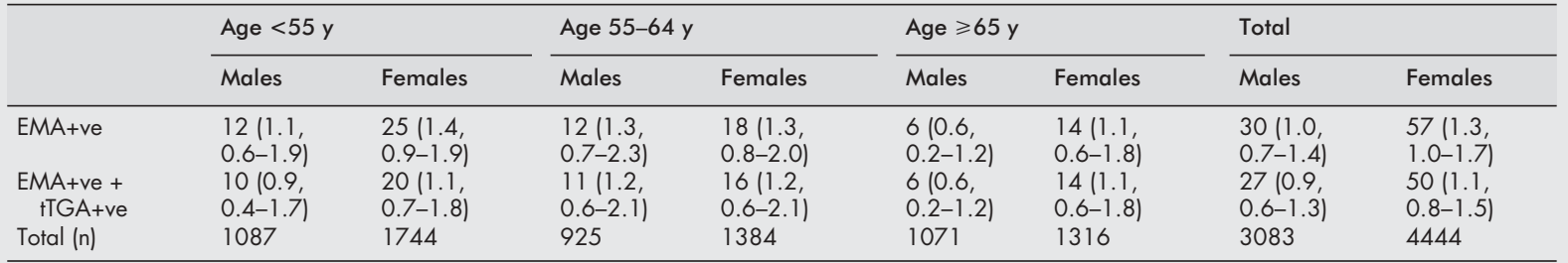

Values are number $(\%, 95 \%$ confidence intervals).

EMA, antiendomysial antibody; TGA, human antitissue transglutaminase antibody. 
Table 2 tTGA results in EMA positive participants considered to have undetected coeliac disease

\begin{tabular}{llr}
\hline & \multicolumn{2}{l}{$E M A+v e$} \\
\cline { 2 - 3 } tTGA category & $n$ & \multicolumn{1}{l}{$\%$} \\
\hline$<3$ & 10 & 11.5 \\
$3-6$ & 11 & 12.6 \\
$>6-10$ & 8 & 9.2 \\
$>10-20$ & 23 & 26.4 \\
$>20$ & 35 & 40.2 \\
Total & 87 & 100
\end{tabular}

EMA, antiendomysial antibody; tTGA, human antitissue transglutaminase antibody.

below the young adult mean. Participants were categorised into those who were anaemic and those who were not (anaemia=haemoglobin in men $<13 \mathrm{~g} / \mathrm{dl}$ and in women $<11.5 \mathrm{~g} / \mathrm{dl})$

\section{Statistical analysis}

Fisher's exact test, $\chi^{2}$ tests, and $\chi^{2}$ tests for trend were used to examine the association between smoking, sociodemographic, and other binary variables, and EMA positivity. Comparisons between EMA positive and EMA negative participants with regard to laboratory, anthropometric, and bone density variables were examined using independent sample $t$ tests. Multivariate analyses were performed to adjust for age, sex, smoking, social class, and other potential confounders using logistic regression for binary and multiple linear regression for continuous dependent variables. We tested biologically plausible interactions, particularly those with sex, by adding multiplicative interaction terms to the multivariate linear regression model. Where data on confounders were missing, these data were modelled as separate categories to ensure nested models contained the same number of participants. All significance tests were two sided and analyses were performed using SPSS version 9.0.

\section{RESULTS}

A total of 20314 individuals were mailed an invitation to participate. Of those mailed, $8515(42 \%)$ agreed to participate. Of those who participated, there were 7550 (89\%) with blood specimens available for serological testing. An overview of the number of participants in the study is shown in fig 1 . There were a total of 7527 participants not previously diagnosed with coeliac disease included in the analyses. Mean age of these participants was 59 years (SD 8.9) and 4444 (59\%) were female. Of the 7440 EMA negative participants, nine had evidence of selective IgA deficiency. Estimates of the seroprevalence of undetected coeliac disease are shown in table 1 . The overall seroprevalence of undetected coeliac disease was 1.2\% (95\% confidence interval (CI) 0.9-1.4) based on EMA positivity alone $(n=87)$ and $1.0 \%(95 \%$ CI $0.8-1.3)$ based on EMA positive and abnormal tTGA results $(\mathrm{n}=77)$. Seroprevalence showed little variation with age or sex. Table 2 shows the distribution of tTGA results in EMA positive participants considered to have undetected coeliac disease. In $75 \%$ of EMA positive participants, tTGA results were unequivocally abnormal ( $>6 \mathrm{U} / \mathrm{ml}$ ). EMA positive participants were less likely to have reported being ex or current smokers (table 3) compared with EMA negative participants, and also showed a trend towards higher social class, although this was not significant at the 5\% level $\left(\chi^{2}\right.$ for trend, $\left.p=0.08\right)$. Mutual adjustment and adjusting for age and sex did not appreciably change these associations.

In univariate analyses, EMA positive participants had lower mean haemoglobin, total protein, corrected calcium, cholesterol, low density lipoprotein, triglyceride, diastolic blood pressure, and weight (all p<0.05) (table 4 ). Mean body mass index (BMI), hip and spine BMD, systolic blood pressure, mean cell volume, and albumin were all slightly lower in participants with undetected coeliac disease but these differences were not significant at the $5 \%$ level. Both alanine aminotransferase and platelet count were higher among EMA positive participants. After adjustment for age, sex, smoking status, and social class, differences in weight and diastolic blood pressure were not significant at the $5 \%$ level.

In the multivariate analyses, undetected coeliac disease was associated with a reduction of $0.5 \mathrm{mmol} / \mathrm{l}(95 \% \mathrm{CI} 0.3-0.8)$ in cholesterol and $0.3 \mathrm{~g} / \mathrm{dl}$ (95\% CI 0.1-0.5) in haemoglobin. For $\mathrm{BMD}$, the mean difference at the hip was $-0.02 \mathrm{~g} / \mathrm{cm}^{2}(95 \% \mathrm{CI}$ -0.05 to +0.02$)$ and at the spine $0.03 \mathrm{~g} / \mathrm{cm}^{2}(95 \% \mathrm{CI}-0.07$ to +0.02 ). There were significant interactions between the effects of EMA result and sex on corrected calcium $(p=0.001)$. Mean corrected calcium was reduced in EMA positive participants among women only $(-0.05 \mathrm{mmol} / \mathrm{l}(95 \% \mathrm{CI}-0.07$ to $-0.02)$ ).

There were no statistically significant associations between undetected coeliac disease and reported morbidity but having high blood pressure, high cholesterol, angina or a heart attack, diabetes, or bronchitis/emphysema all appeared to be less common in those who were EMA positive (table 5). In 75 of 85

Table 3 Sociodemographic and smoking characteristics of study participants by antiendomysial antibody (EMA) result

\begin{tabular}{|c|c|c|c|c|}
\hline & \multirow[b]{2}{*}{ EMA-ve (n (\%)) } & \multirow[b]{2}{*}{$E M A+v e(n(\%))$} & \multicolumn{2}{|c|}{ Odds ratio for positive EMA test $(95 \% \mathrm{Cl})$} \\
\hline & & & Univariate & Multivariate* \\
\hline \multicolumn{5}{|l|}{ Sex } \\
\hline Female & 4387 (59.0) & $57(65.5)$ & 1.0 & 1.0 \\
\hline Male & $3053(41.0)$ & $30(35.5)$ & $0.76(0.49-1.18)$ & $0.83(0.52-1.32)$ \\
\hline \multicolumn{5}{|l|}{ Age group (y) } \\
\hline$<55$ & $2794(37.6)$ & $37(42.5)$ & 1.0 & 1.0 \\
\hline $55-64$ & $2280(30.6)$ & $30(34.5)$ & $0.99(0.61-1.61)$ & $1.01(0.62-1.65)$ \\
\hline$\geqslant 65$ & $2366(31.8)$ & $20(23.0)$ & $0.64(0.37-1.10)$ & $0.67(0.38-1.16)$ \\
\hline \multicolumn{5}{|l|}{ Social class group } \\
\hline Professional & $3573(48.0)$ & $49(56.3)$ & 1.0 & 1.0 \\
\hline Skilled & $3011(40.5)$ & $32(34.5)$ & $0.78(0.50-1.21)$ & $0.82(0.52-1.29)$ \\
\hline Partly skilled and unskilled & $649(8.7)$ & $4(4.6)$ & $0.45(0.16-1.25)$ & $0.51(0.18-1.43)$ \\
\hline Missing values & $207(2.8)$ & $2(2.3)$ & & \\
\hline \multicolumn{5}{|l|}{ Smoking status } \\
\hline Never & $3371(45.3)$ & $52(59.8)$ & 1.0 & 1.0 \\
\hline Ex & $3024(40.6)$ & $30(34.5)$ & $0.64(0.41-1.01)$ & $0.71(0.45-1.14)$ \\
\hline Current & 958 (12.9) & $5(5.7)$ & $0.34(0.14-0.85)$ & $0.36(0.14-0.90)$ \\
\hline Missing values & $87(1.2)$ & $0(0)$ & & \\
\hline
\end{tabular}


Table 4 Distribution of selected physiological variables by antiendomysial antibody (EMA) test result

\begin{tabular}{|c|c|c|c|c|}
\hline \multirow[b]{2}{*}{ Dependent variable } & \multirow{2}{*}{$\begin{array}{l}\text { EMA-ve } \\
(\text { mean }(n))\end{array}$} & \multirow{2}{*}{$\begin{array}{l}\text { EMA+ve } \\
\text { (mean (n)) }\end{array}$} & \multicolumn{2}{|c|}{ Mean (SEM) difference } \\
\hline & & & Univariate & Multivariate $†$ \\
\hline Haemoglobin (g/dl) & 13.7 (7425) & $13.3(87)$ & $-0.4(0.2)^{* *}$ & $-0.3(0.1)^{* *}$ \\
\hline Mean cell volume (fl) & 89.4 (7423) & 88.9 (87) & $-0.6(0.6)$ & $-0.4(0.5)$ \\
\hline Platelet count $\left(\times 10^{9} / \mathrm{l}\right)$ & 260.9 (7406) & 279.7 (87) & $18.8(9.2)^{*}$ & $18.2(6.5)^{* *}$ \\
\hline Total protein (g/l) & 71.1 (7436) & 70.2 (87) & $-0.9(0.5)^{*}$ & $-1.0(0.5)^{*}$ \\
\hline Albumin (g/l) & 42.0 (7438) & 42.0 (87) & $-0.1 \quad(0.4)$ & $-0.3(0.4)$ \\
\hline Alkaline phosphatase (IU/I)‡ & 161.9 (7438) & 163.6 (87) & $1.0(0.9-1.1)$ & $1.0(1.0-1.1)$ \\
\hline Alanine aminotransferase (IU/I)‡ & 16.7 (7438) & 20.8 (87) & $1.2(1.1-1.4)^{* *}$ & ** $1.2(1.1-1.4)^{* *}$ \\
\hline Corrected calcium (mmol/l) & $2.33(7431)$ & $2.30(87)$ & $-0.03(0.01)^{*}$ & $-0.02(0.01)^{*}$ \\
\hline Cholesterol (mmol/l) & $6.4(7430)$ & $5.8 \quad(86)$ & $-0.6(0.1)^{* *}$ & $-0.5(0.1)^{* *}$ \\
\hline High density lipoprotein (mmol/l) & 1.2 (6838) & $1.1 \quad(82)$ & $-0.02(0.04)$ & $-0.05(0.04)$ \\
\hline Low density lipoprotein (mmol/l) & $4.4(6654)$ & $4.1 \quad(81)$ & $-0.3(0.1)^{*}$ & $-0.3(0.1)^{*}$ \\
\hline Weight $(\mathrm{kg})$ & $71.6 \quad(7428)$ & $68.6(87)$ & $-2.9(1.4)^{* *}$ & $-2.2(1.2)$ \\
\hline Height $(\mathrm{cm})$ & 166.4 (7427) & 166.0 & $-0.5(1.0)$ & $-0.1 \quad(0.7)$ \\
\hline Body mass index $\left(\mathrm{kg} / \mathrm{m}^{2}\right)$ & $25.8(7425)$ & 25.0 (87) & $-0.8(0.4)$ & $-0.7 \quad(0.4)$ \\
\hline Systolic blood pressure (mm Hg) & $137.0 \quad(7417)$ & 134.1 (87) & $-3.0 \quad(2.2)$ & $-1.6(2.0)$ \\
\hline Diastolic blood pressure (mm Hg) & 82.5 (7417) & 80.1 (87) & $-2.4(1.1)^{*}$ & $-1.9 \quad(1.2)$ \\
\hline Total spine $B M D\left(\mathrm{~g} / \mathrm{cm}^{2}\right)$ & $0.97(5035)$ & $0.94(58)$ & $-0.03(0.02)$ & $-0.03(0.02)$ \\
\hline Total hip BMD $\left(\mathrm{g} / \mathrm{cm}^{2}\right)$ & $0.90(5024)$ & $0.88(58)$ & $-0.02(0.02)$ & $-0.02(0.02)$ \\
\hline \multicolumn{5}{|c|}{$\begin{array}{l}\text { †Adjusted for age group, sex, social class group, and smoking status. } \\
\neq \text { Values presented for these variables are geometric mean, ratio of geometric means, and } 95 \% \text { confidence } \\
\text { intervals. } \\
\text { BMD, bone mineral density. } \\
{ }^{*} p<0.05 ;{ }^{*} p<0.01 \text {. }\end{array}$} \\
\hline
\end{tabular}

(88\%) EMA positive participants and 5527 of 7015 (79\%) EMA negative participants, general health was reported as "good or excellent", giving an odds ratio of 1.76 (95\% CI 0.90 3.46) adjusted for age, sex, social class, and smoking status. There was no difference in the proportion of deaths recorded (EMA negative 591 (7.9\%); EMA positive $5(5.7 \%) ; \chi^{2} \mathrm{p}=0.6$ ). Underlying causes of death given for the five EMA positive participants were carcinoma of the pancreas, acute myeloid leukaemia, ischaemic heart disease, carcinoma of the cervix, and B cell lymphoma (not otherwise specified).

Fourteen of 87 (16.1\%) EMA positive participants and 315 of $7425(4.2 \%)$ EMA negative participants were found to be anaemic, giving an odds ratio of 4.56 (95\% CI 2.53-8.21) adjusted for age, smoking status, sex, and social class. Of the EMA positive anaemic participants, nine were women (haemoglobin range $10.1-11.3 \mathrm{~g} / \mathrm{dl}$ ) and five were men (haemoglobin range $11.6-12.8 \mathrm{~g} / \mathrm{dl}$ ). In seven of $58(12.1 \%)$ EMA positive participants and 311 of 5024 (6.2\%) EMA negative participants, BMD at the hip showed osteoporosis, giving an odds ratio of 3.08 (95\% CI 1.31-7.25) adjusted for age, BMI, smoking status, and social class.

\section{DISCUSSION}

Our study shows that undetected coeliac disease, as assessed by EMA positivity, affects approximately $1 \%$ of this general population sample aged $45-76$ years. In comparison with earlier screening studies, the number of EMA positive participants was sufficiently large to use data collected at recruitment for comparisons with EMA negative participants. Although positive participants were more likely to assess their own health as good or excellent than negative participants, some were mildly anaemic (16\%) or had evidence of osteoporosis (12\%). In contrast, they had a more favourable cardiovascular risk profile in terms of lower cholesterol levels, slightly lower blood pressure, and smoking less than EMA negative participants.

\section{Limitations and merits}

Unlike earlier studies, it was not possible to confirm the diagnosis of coeliac disease by intestinal biopsy in EMA positive participants. The validity of our findings therefore is dependent on the specificity and sensitivity of the EMA test. In routine clinical practice the test has proved to be extremely accu- rate, with a sensitivity of $94 \%$ and a specificity of $99 \%$ quoted recently. ${ }^{17}$ Recent data from our laboratory in Derby (unpublished) has estimated a specificity of $99.8 \%$ based on 1468 EMA tests. In earlier screening studies a total of 57 participants were found to be EMA positive and in all but three a diagnosis of coeliac disease was supported by abnormal biopsy findings. ${ }^{3-11}$ The recent introduction of the human tTGA assay in our laboratory allowed us to confirm that $89 \%$ (77/87) of EMA positives also had an abnormal tTGA level. Therefore, while it is possible that a few of the EMA positive participants did not have abnormal intestinal histology, the results of the tTGA assay indicate this is likely to be at most $11 \%$. In addition, the sensitivity of the EMA test means that approximately $5 \%$ of those with coeliac disease will not have been detected.

We chose not to restrict our analyses to those positive for both tests for two reasons. Firstly, the sensitivity of human tTGA is not yet well established; a value of $96 \%$ has been estimated recently. ${ }^{18}$ Secondly, tTGA testing was performed only on EMA positive subjects whereas EMA testing was performed on the whole sample. When we compared those with both EMA positive and abnormal tTGA results to EMA negative participants, the associations presented here were of similar magnitude and in the same direction. None of the associations was changed towards the null.

Although this was a general population sample, there were greater numbers of women and those from higher social class groups, which is likely to be a consequence of the response rate to the original mailed invitation. We have no information about non-responders but it seems unlikely that those people who agreed to participate were, in some way, more likely to have undetected coeliac disease and therefore biased our findings towards an overestimate. Indeed, our seroprevalence estimate is similar to the findings of others who have performed smaller screening studies in the UK. ${ }^{419}$

\section{Interpretation}

As might be expected with undetected coeliac disease, mean haemoglobin, corrected calcium, and total protein levels were lower in EMA positive participants and $16 \%$ had a mild anaemia compared with $4 \%$ of EMA negative participants. Increases in serum alanine aminotransferase and platelet counts were small but similar to those found in clinically 
Table 5 Relation between participants with positive antiendomysial antibody (EMA) test result and reported morbidity

\begin{tabular}{|c|c|c|c|c|}
\hline \multirow[b]{2}{*}{ EMA result } & \multicolumn{2}{|c|}{ Reported morbidity } & \multicolumn{2}{|c|}{ Odds ratio $(95 \% \mathrm{Cl})$} \\
\hline & No (n (\%)) & Yes (n (\%)) & Univariate & p Value* \\
\hline \multicolumn{5}{|c|}{ High blood pressuret } \\
\hline Negative & $5876(81.4)$ & $1347(18.6)$ & 1.0 & \\
\hline Positive & 73 (83.9) & $14(16.1)$ & $0.84(0.47-1.49)$ & 0.6 \\
\hline \multicolumn{5}{|c|}{ High blood cholesterol } \\
\hline Negative & $6188(87.6)$ & 875 (12.4) & 1.0 & \\
\hline Positive & 81 (93.1) & $6(6.9)$ & $0.52(0.23-1.20)$ & 0.2 \\
\hline \multicolumn{5}{|l|}{ Stroke } \\
\hline Negative & 7149 (98.5) & $109(1.5)$ & 1.0 & \\
\hline Positive & 85 (97.7) & $2(2.3)$ & $1.54(0.37-6.35)$ & 0.4 \\
\hline \multicolumn{5}{|c|}{ Heart attack and/or angina } \\
\hline Negative & 6778 (93.3) & $487(6.7)$ & 1.0 & \\
\hline Positive & 85 (97.7) & $2(2.3)$ & $0.33(0.08-1.34)$ & 0.2 \\
\hline \multicolumn{5}{|c|}{ CVS combined } \\
\hline Negative & $5570(76.6)$ & 1701 (23.4) & 1.0 & \\
\hline Positive & 70 (80.5) & 17 (19.5) & $0.79(0.47-1.35)$ & 0.5 \\
\hline \multicolumn{5}{|c|}{ Thyroid disease } \\
\hline Negative & $6806(93.8)$ & $446(6.2)$ & 1.0 & \\
\hline Positive & $80(92.0)$ & $7(8.0)$ & $1.33(0.61-2.91)$ & 0.6 \\
\hline \multicolumn{5}{|l|}{ Diabetes } \\
\hline Negative & 7049 (97.2) & $202(2.8)$ & 1.0 & \\
\hline Positive & 86 (98.9) & $1(1.1)$ & $0.41(0.06-2.93)$ & 0.7 \\
\hline \multicolumn{5}{|c|}{ Fracture of the wrist } \\
\hline Negative & 6806 (93.8) & $452(6.2)$ & 1.0 & \\
\hline Positive & 80 (92.0) & 7 (8.0) & $1.32(0.60-2.87)$ & 0.6 \\
\hline \multicolumn{5}{|c|}{ Bronchitis/emphysema } \\
\hline Negative & 6125 (84.7) & 1110 (15.3) & 1.0 & \\
\hline Positive & 79 (90.8) & $8(9.2)$ & $0.56(0.27-1.16)$ & 0.2 \\
\hline \multicolumn{5}{|l|}{ Asthma } \\
\hline Negative & $6520(90.1)$ & $720(9.9)$ & 1.0 & \\
\hline Positive & $78(89.7)$ & $9(10.3)$ & $1.04(0.52-2.09)$ & 1.0 \\
\hline \multicolumn{5}{|l|}{ Cancer } \\
\hline Negative & 6853 (94.5) & $396(5.5)$ & 1.0 & \\
\hline Positive & $82(94.3)$ & $5(5.7)$ & $1.05(0.43-2.62)$ & 0.8 \\
\hline
\end{tabular}

diagnosed coeliac disease. ${ }^{20}{ }^{21}$ While there have been reports of significant decreases in BMD in screen detected or subclinical coeliac disease, we found only a small non-significant decrease in BMD. ${ }^{12}{ }^{13}$ However, the prevalence of osteoporosis defined according to World Health Organisation criteria was $12 \%$ in EMA positives, twice that of EMA negatives.

EMA positive participants did not regard themselves as unwell; indeed, the numbers reporting good or excellent health were greater than in EMA negatives, although this difference was not statistically significant. Reported morbidity was no greater in positives and there was a trend towards less cardiovascular morbidity. Our finding of an $8 \%$ reduction in serum cholesterol among EMA positive participants would be expected to have a significant impact on cardiovascular morbidity. It has been estimated that a $0.6 \mathrm{mmol} / \mathrm{l}$ lower cholesterol will confer a $25 \%$ reduction in the incidence of ischaemic heart disease. ${ }^{22}$ Our data suggest that undetected coeliac disease may afford protection from ischaemic heart disease, a hypothesis first raised by Whorwell et al some 25 years ago. ${ }^{23}$

We found that few of the EMA positives were smokers and that as a group they reported much less smoking in the past. Three published case control studies have examined the relationship between cigarette smoking and coeliac disease. While two found a positive association between not smoking or never smoking and having coeliac disease, the most recent study did not. ${ }^{24-26}$ In these studies it was not clear how much of the association might be accounted for by selection and reporting biases and by cases stopping smoking after diagnosis. Such considerations do not apply here and our findings suggest that this is indeed a causal relationship, probably analogous to that seen in ulcerative colitis.

In conclusion, we found that undetected coeliac disease is likely to affect approximately $1 \%$ of the general population in
England. Although these participants are at increased risk of mild anaemia and osteoporosis, they do not regard themselves as unwell. The important finding of a favourable cardiovascular risk profile in these individuals suggests that any screening programme of the general population would need to be carefully evaluated in terms of risks and benefits before its introduction.

\section{ACKNOWLEDGEMENTS}

We thank Kathleen Eley, Lesley Bird, and Sylvia Attah for their help with processing the blood samples. KTK and RR were responsible for the original study in Cambridge. JW, RFAL, PGH, GKTH, and AL designed and managed the study in Derby. JW, SL, and RH planned and performed the statistical analyses. All authors contributed to the writing of the manuscript. We thank Coeliac UK and the Wellcome Trust for funding.

\section{Authors' affiliations}

J West, R F A Logan, University of Nottingham, Division of Epidemiology and Public Health, Medical School, Queen's Medical Centre, Nottingham NG7 2UH, UK

P G Hill, A Lloyd, Department of Chemical Pathology, Southern Derbyshire Acute Hospitals NHS Trust, Derby, UK

S Lewis, R Hubbard, University of Nottingham, Division of Medical and Surgical Sciences, Clinical Sciences Building, Nottingham City Hospital, Nottingham, UK

R Reader, K-T Khaw, Clinical Gerontology Unit, University of Cambridge School of Clinical Medicine, Addenbrooke's Hospital, Cambridge, UK

G K T Holmes, Department of Gastroenterology, Southern Derbyshire Acute Hospitals NHS Trust, Derby, UK

\section{REFERENCES}

1 Chorzelski TP, Beutner EH, Sulej J, et al. IgA anti-endomysium antibody. A new immunological marker of dermatitis herpetiformis and coeliac disease. Br J Dermatol 1984;111:395-402. 
2 Dieterich W, Laag E, Schopper H, et al. Autoantibodies to tissue transglutaminase as predictors of celiac disease. Gastroenterology 1998:115:1317-21.

3 Ivarsson A, Persson LA, Juto $P$, et al. High prevalence of undiagnosed coeliac disease in adults: a Swedish population-based study. J Intern Med 1999;245:63-8.

4 Johnston SD, Watson RG, McMillan SA, et al. Prevalence of coeliac disease in Northern Ireland. Lancet 1997;350:1370.

5 Kolho KL, Farkkila MA, Savilahti E. Undiagnosed coeliac disease is common in Finnish adults. Scand J Gastroenterol 1998;33:1280-3.

6 Riestra S, Fernandez E, Rodrigo L, et al. Prevalence of Coeliac disease in the general population of northern Spain. Strategies of serologic screening. Scand J Gastroenterol 2000;35:398-402.

7 Volta U, Bellentani S, Bianchi FB, et al. High prevalence of celiac disease in Italian general population. Dig Dis Sci 2001:46:1500-5.

8 Cook HB, Burt M, Collett JA, et al. Adult coeliac disease: prevalence and clinical significance. J Gastroenterol Hepatol 2000;15:1032-6.

9 Couignoux S, Ocmant A, Cottel D, et al. Prevalence of adult coeliac disease in Northern France. Gut 2000;47(suppl III):A196.

10 Hovell CJ, Collett JA, Vautier G, et al. High prevalence of coeliac disease in a population-based study from Western Australia: a case fo screening? Med J Aust 2001;175:247-50.

11 Gomez JC, Selvaggio GS, Viola M, et al. Prevalence of celiac disease in Argentina: screening of an adult population in the La Plata area. Am J Gastroenterol 2001:96:2700-4.

12 Corazza GR, Di Sario A, Cecchetti L, et al. Influence of pattern of clinical presentation and of gluten-free diet on bone mass and metabolism in adult coeliac disease. Bone 1996;18:525-30.

13 Mustalahti K, Collin P, Sievanen H, et al. Osteopenia in patients with clinically silent coeliac disease warrants screening (letter). Lancet 1999.354.744-5.

14 Trivedi DP, Khaw KT. Bone mineral density at the hip predicts mortality in elderly men. Osteoporos Int $2001 ; 12: 259-65$.
15 May H, Murphy S, Khaw KT. Bone mineral density and its relationship to skin colour in Caucasian females. Eur J Clin Invest 1995;25:85-9.

16 May H, Murphy S, Khaw KT. Age-associated bone loss in men and women and its relationship to weight. Age Ageing 1994;23:235-40.

17 James MW, Scott BB. Endomysial antibody in the diagnosis and management of coeliac disease. Postgrad Med J 2000;76:466-8.

18 Burgin-Wolff A, Dahlbom I, Hadziselimovic F, et al. Antibodies against human tissue transglutaminase and endomysium in diagnosing and monitoring coeliac disease. Scand J Gastroenterol 2002;37:685-91.

19 Sanders DS, Carter M, Hurlstone DP, et al. Association of adult coeliac disease with irritable bowel syndrome: a case-control study in patients fulfilling ROME II criteria referred to secondary care. Lancet 2001;358:1504-8.

20 Logan RF, Tucker G, Rifkind EA, et al. Changes in clinical features of coeliac disease in adults in Edinburgh and the Lothians 1960-79. BM 1983;286:95-7.

21 Bardella MT, Fraquelli M, Quatrini $M$, et al. Prevalence of hypertransaminasemia in adult celiac patients and effect of gluten-free diet. Hepatology 1995;22:833-6.

22 Law MR, Wald NJ, Thompson SG. By how much and how quickly does reduction in serum cholesterol concentration lower risk of ischaemic heart disease? BM 1994;308:367-72.

23 Whorwell PJ, Alderson MR, Foster KJ, et al. Death from ischaemic heart-disease and malignancy in adult patients with coeliac disease. Lancet 1976;2:113-14.

24 Snook JA, Dwyer L, Lee-Elliott C, et al. Adult coeliac disease and cigarette smoking. Gut 1996;39:60-2.

25 Patel AH, Loftus EV Jr, Murray JA, et al. Cigarette smoking and celiac sprue: a case- control study. Am J Gastroenterol 2001:96:2388-91.

26 Vazquez H, Smecuol E, Flores D, et al. Relation between cigarette smoking and celiac disease: evidence from a case-control study. Am J Gastroenterol $2001 ; 96: 798-802$ 